\title{
SIMULATION-BASED UTILITY ASSESSMENT OF REAL-TIME INFORMATION FOR SUSTAINABLE MINING OPERATIONS
}

\author{
Sai Srinivas Nageshwaraniyer \\ Chao Meng \\ Young-Jun Son \\ Systems and Industrial Engineering \\ The University of Arizona \\ Tucson, AZ 85721, USA
}

\author{
Sean Dessureault \\ Mining and Geological Engineering \\ The University of Arizona \\ Tucson, AZ 85721, USA
}

\begin{abstract}
In capital intensive industries such as coalmines, real-time information is useful to run their operations within sustainable limits, and to enable early detection and response to deviations from those limits. The goal of this research is to assess the utilities of real-time information collected in coalmines for operating within sustainable limits. In this work, one of the largest coalmines in North America is considered. Utility indices are first proposed for important real-time information from the coalmine. Attributes are then defined for the indices and expressions for utility are proposed. The indices are also classified based on their impact on economic, social or environmental dimensions of sustainability of the coalmine. Experiments are conducted using real-time data on a simulation model of the material handling network of the coalmine to assess one of the proposed indices. The proposed index is found to precisely indicate utility of the corresponding real-time information.
\end{abstract}

\section{INTRODUCTION}

In the USA, coal is a major energy resource, constituting about 32 percent of total energy production and 23 percent of total energy consumption. This is equivalent to 1.05 billion tons in 2010 (U.S. Energy Information Administration 2011). This popularity of coal is attributed to its low price per BTU compared with other resources such as petroleum and natural gas. Consequently, coal mining is a major industry in the USA employing 134,000 people (National Mining Association 2011). USA was a net exporter of coal in 2010, where the surplus of coal exports over imports was $5.7 \%$ of the total coal mined in 2010 (U.S. Energy Information Administration 2011). Thus, coal mining empowers the economy of the USA, providing a lot of jobs. However, coal mining at the same time puts stress on the environment surrounding the mine and the companies that use coal. In surface mining, earth's surface is removed till the coal seams are reached. This surface mining of coal impacts the environment negatively in the following ways: destruction of the landscape; degradation of the visual environment; disturbance of surface water and groundwater; destruction of agricultural and forest lands; damage to recreational lands; noise pollution; dust; truck traffic; sedimentation and erosion; land subsidence; and vibration from blasting (Miller 2011). The environmental costs associated with the continued growth of the mining industry are not well understood. An analysis of the waste rock production and ore decline trends in the Australian mining industry using historical data pointed out that the environmental costs per unit mineral production in terms of energy, water, greenhouse emissions would be significantly increasing in the future (Mudd 2009). Therefore, there is a need to plan the coalmining operations to minimize their detrimental effects on the environment.

At the United Nations World Summit in 2005, the satisfaction of economic, social and environmental demands was defined as three pillars of sustainability (United Nations General Assembly 2005). There is a need for mining companies to plan coal mining operations that can positively impact sustainability on the dimensions of sustainability represented by the three pillars mentioned above. In the current paper, it 
is assumed that any specific coalmining operation each of whose outputs are within desirable limits specified using one of the three pillars is operating within sustainable operating limits. Such an operation is said to belong to the category of sustainable operations. Sustainable operations should be able to decrease negative impact, prolong the life of the environmental resources, strive for the welfare of the society that forms its workforce, and the well-being of its economy. The main environmental resources surrounding the coal mines are air, water, land and vegetation. Coal mining operations have to be planned in a way that the negative impacts on the environment, the health of its workforce and people living nearby due to air and water pollutions in the surrounding land arising from it are at a minimum. At the same time they have to be planned with an aim to reduce costs incurred and prolong the life of the mining company through profits to positively impact its economy.

A company's competitive advantage depends upon its ability to accumulate, generate, deploy and secure unique and valuable resources (Bamey 1991). It has to make its operations sustainable for gaining competitive edge. An important resource to the company is its operational information generated, stored and used to monitor, plan and take decisions. Information is to be utilized by the company to enable it to operate within sustainable limits and minimize the delay to respond to deviations from those limits. To respond to the problems of 1) evaluating completeness of real-time information to enable coalmines to plan to operate within sustainable limits, and 2) evaluating most appropriate update frequency to balance the cost incurred in storing and updating information, and minimize delay to respond to deviations from sustainable operating limits, the goal of this research is to assess the utilities of different real-time information collected in coalmines through indices. In the current paper, thirteen indices are proposed to indicate the utilities of different types of real-time information from a coalmine in North America to enable the coalmine to operate within sustainable limits. For each index, six types of attributes are defined to represent different dimensions of the information, which include 1) name, 2) impacter, 3) impacter limits, 4) number of information sources for each impacter, 5) update frequencies from each source, and 6) utility. The proposed thirteen indices are classified into five categories based on the dimension of sustainability (economic, social and environmental) that their information impacts and their nature (operational and non-operational). Utility of information is quantified on the basis of its completeness, its ability to reduce the delay to respond to changes in the operating limits beyond the sustainable limits and it is updated more frequently than required thereby incurring maintenance costs in addition to cost of updating information. Completeness of information is defined in this paper is the number of active information sources from all the listed information sources. Therefore in assessing utility, both the positive aspect of utilization of information and negative aspect of update frequency are considered.

In this work, an extensive discrete-event simulation model of the material handling network of the mine is constructed in Arena and used to assess one of the proposed indices under different settings. Specifically, it is used to obtain the value of the impacter corresponding to that index, as an output from simulation. In general discrete-event simulation is a useful tool for modeling complex systems in logistics, material handling and transportation areas. Since the simulation model can represent the detailed behavior including uncertainty of the real system, it can more precisely capture means and ranges of the desired outputs when compared to methodologies that approximate the behavior of the real system. Furthermore, simulations in our study are run using real-time data obtained via sensors and stored in data warehouse that is located remotely at the real coalmine. Figure 1 displays the control center constructed at The University of Arizona in the Mining and Geological Engineering department, which displays realtime information obtained from the coalmine as well as a simulation model of the material handling network of the mine in different monitor screens (Nageshwaraniyer et al. 2011). Comprehensive experiments to assess the proposed utility indices for different real-time information will be conducted at the control center.

The remainder of this paper is structured as follows. Section 2 contains a brief literature review on the important topics discussed in the current paper. A brief background on the coalmine considered as case study is then provided in Section 3. In Section 4, the definitions and classifications are provided for utility indices proposed in the current paper. The simulation model of the material handling network of 
the coalmine is described in Section 5. Experiments performed using the simulation model to assess one of the proposed indices is also described in Section 5. Section 6 contains contributions of the current paper and ideas for future research.

\section{LITERATURE REVIEW}

The impact of surface mining throughout the important stages of the product life cycle of coal is summarized in Table 1. The coal mining category includes the sequence of material handling operations from coal excavation to coal loading for delivery to customer excluding coal preparation. The coal preparation category includes activities to remove various impurities and potential pollutants. The coal transportation category includes the sequence of material handling operations from loading of coal onto transit vehicles, transit of coal and unloading of coal from transit vehicles at the customer location. The coal consumption category includes the effects of coal combustion at the customer's location, and the land reclamation category considers the effect due to water penetration after surface mining on the reclaimed land. The information in Table 1 is classified into action, particle/agent and effect columns. Action refers to the specific operation in surface mining that impacts the environment. Particle/Agent is the output from the action that causes the effect. The information on the type of pollution that is caused or the component of the environment (land, water, air) affected by the Action/Particle/Agent is given in the Effects column.

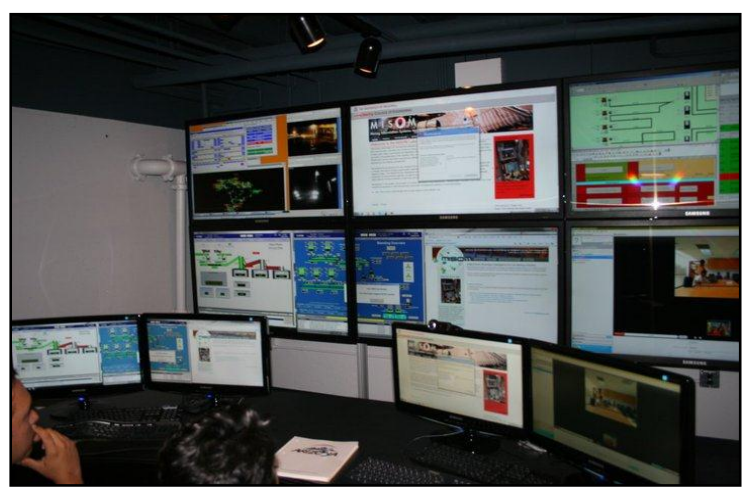

Figure 1: Control center (Nageshwaraniyer et al. 2011)

Sustainable development is the development that should meet the needs of the present without compromising the ability of future generations to meet their own need (Oxford University Press 1987). The concept of sustainability is seen by many researchers as an idea to pursue in order to attack the possible limitation of the economical growth due to the increasing environmental load caused by the human community on the nature (Tomiyama 2001). In the context of coal mining, the over mining of coal is to be curtailed to store non-renewable energy for future generations and to minimize the detrimental effects of the coal mining operations on the resources surrounding coal mine (air, water, land and vegetation) that are important for living. Cumulative impacts arising from multiple coal mining operations in Australia, and the management and assessment approaches used to mitigate negative or enhance positive impacts on the environment is investigated in (Franks 2008). These approaches from working examples included: project based cumulative assessment, information and data sharing, mitigation and enhancement programs, collective monitoring among others. It is found that proactive management and assessment has the potential to benefit regional environments. However, as these approaches are conceptual and new, their actual utilities on the cumulative impacts on the environment can only be judged in the future. A generic framework for indicators of sustainable development of the individual companies within the mining and minerals industries and that whole sector, through performance assessment and improvement, is proposed in (Azpagic 2004). The indicators are developed 
for metallic, construction and industrial minerals sub-sectors and for some of the energy minerals like coal. A simplified framework of indicators is needed for small-to-medium size mining companies.

Table 1: Summary of effects of coal mining on the environment

\begin{tabular}{|c|c|c|c|}
\hline $\begin{array}{l}\text { Life Cycle } \\
\text { Category }\end{array}$ & Action(s) & Particle (s)/Agent (s) & Effect(s) \\
\hline \multirow{5}{*}{$\begin{array}{l}\text { Coal mining } \\
\text { (Surface } \\
\text { mining } \\
\text { process) }\end{array}$} & $\begin{array}{l}\text { Surface mining as } \\
\text { a whole }\end{array}$ & Dust & $\begin{array}{l}\text { Air pollution (Irving and Tailakov 1999). World Bank Group (1998) } \\
\text { reports dust generation of } 0.1 \text { and } 0.06 \text { tons per } 1,000 \text { tons of coal } \\
\text { produced for contour and area mining, respectively. }\end{array}$ \\
\hline & Surface removal & Methane & $\begin{array}{l}\text { Air pollution } 0.3 \text { to } 2 \text { cubic meters of methane per metric ton of coal } \\
\text { mined (Irving and Tailakov 1999) }\end{array}$ \\
\hline & Surface removal & Action itself & $\begin{array}{l}\text { Channel erosion; decreases ground water storage; drains shallow seam } \\
\text { aquifers (Sengupta 1993) }\end{array}$ \\
\hline & Surface removal & Liquid Effluents & $\begin{array}{l}\text { Contour and area mining generate } 0.24 \text { and } 1.2 \text { tons of liquid effluents } \\
\text { per } 1,000 \text { tons of coal produced, respectively, compared to } 1 \text { and } 1.6 \\
\text { tons, respectively, for conventional and longwall mining operations } \\
\text { (Irving and Tailakov 1999) }\end{array}$ \\
\hline & Surface removal & Solid Waste & $\begin{array}{l}10 \text { tons of solid waste produced per } 1,000 \text { tons of coal removed for both } \\
\text { contour and area mining (World Bank Group 1998) }\end{array}$ \\
\hline \multirow{3}{*}{$\begin{array}{c}\text { Coal } \\
\text { preparation }\end{array}$} & $\begin{array}{l}\text { Coal combustion } \\
\text { in thermal dryers }\end{array}$ & $\begin{array}{l}\text { Entrained dust containing coal, ash and various } \\
\text { gases; }\end{array}$ & Air pollution (Lucas, Maneval and Foreman 1979) \\
\hline & Waste discharge & Fine coal, coal refuse & $\begin{array}{l}\text { Causes water pollution when let out into stream (Lucas, Maneval and } \\
\text { Foreman 1979) }\end{array}$ \\
\hline & $\begin{array}{l}\text { Disposal of refuse } \\
\text { in impoundments }\end{array}$ & $\begin{array}{l}\text { Refuse (unsalable coal, shale, bone, calcite, } \\
\text { gypsum, clay, pyrite, or marcasite) }\end{array}$ & $\begin{array}{l}\text { Non productive use of land; loss of aesthetic value; danger of slides; dam } \\
\text { failures; water pollution (Lucas, Maneval and Foreman 1979) }\end{array}$ \\
\hline \multirow{3}{*}{$\begin{array}{l}\text { Coal } \\
\text { transportation }\end{array}$} & Coal loading & & $\begin{array}{l}\text { Estimated } 0.02 \text { percent is lost as fugitive dust during loading (Chadwick } \\
\text { et al. 1987) }\end{array}$ \\
\hline & $\begin{array}{c}\text { Coal transport to } \\
\text { customers }\end{array}$ & & $\begin{array}{l}\text { Estimated } 0.05 \text { to } 1 \text { percent of the coal is lost during transit (Chadwick et } \\
\text { al. 1987) }\end{array}$ \\
\hline & Coal unloading & & $\begin{array}{l}\text { Estimated } 0.02 \text { lost during unloading. Actual amount depends on mode } \\
\text { of transit and length of trip (Chadwick et al. 1987) }\end{array}$ \\
\hline \multirow[b]{2}{*}{$\begin{array}{c}\text { Coal } \\
\text { consumption }\end{array}$} & \multirow[b]{2}{*}{ Coal combustion } & $\begin{array}{l}\text { Emits Sulfur dioxide (SO2), particulate matter } \\
\text { (PM), Carbon dioxide (CO2) }\end{array}$ & Affects environment, particularly ground-level (Miller 2011) \\
\hline & & $\begin{array}{l}\text { Residue (fly ash, bottom ash, boiler slag, } \\
\text { synthetic gypsum contains gypsum }\left(\mathrm{CaSO}_{4}\right) \text { and } \\
\text { calcium sulfite }\left(\mathrm{CaSO}_{3}\right) \text { but can also contain fly } \\
\text { ash and unreacted lime or limestone) }\end{array}$ & $\begin{array}{l}\text { Some residue used while others discarded; becomes waste when } \\
\text { discarded (Miller 2011) }\end{array}$ \\
\hline $\begin{array}{c}\text { Land } \\
\text { reclamation }\end{array}$ & $\begin{array}{l}\text { Water penetration } \\
\text { in reclaimed land }\end{array}$ & Water & $\begin{array}{l}\text { Movement of high concentration of salts into existing or reestablished } \\
\text { aquifer systems (Schmiermund and Drozd 1997) }\end{array}$ \\
\hline
\end{tabular}

Utility indices are proposed for real-time information from a coalmine to help it to operate within sustainable limits. Information is an important tool to help a company operate within sustainable limits. The management of information resources within economical, ecological and social dimensions could balance profit maximization and stakeholder interests. Increasing the number of activities dedicated to impacting sustainability positively increases cost but lowers calculated expenditures due to decline in stakeholder risks (Schmidt et al. 2009).

\section{CASE STUDY}

The case study for the current paper is one of the most productive coalmines in North America. The considered coalmine is active throughout the year. A typical day at the coalmine is divided into two twelve hour shifts. On an average 12 trains arrive each shift at the mine and coal is transported via trains to customers across the USA. More than 300,000 tons of coal per day is excavated and shipped out. Figure 2 provides an overview of the material handling operations at the coal mine and its components that affect the economic, social and environmental dimensions of sustainability. At the center of Figure 2 the coal flow direction in the mine from excavation of coal to loading of customer trains is illustrated. Pits are natural and huge repositories of coal. Coal is excavated at pits using equipments known as shovels. At any point of time there are about 4 to 8 shovels active at the mine. Empty trucks are routed to shovels and loaded with coal. Trucks loaded with coal are routed to coal dumps known as crushers or hoppers. There are four hoppers at the coalmine. Coal dumped into hoppers is crushed and routed via conveyors to huge tanks called silos that contain coal. There are six silos in the mine and five silos are of 14,000 tons capacity while the sixth silo is of 35,000 tons capacity. Coal is routed from silos via conveyors to destinations known as loadouts. There are two loadouts at the coalmine, and at a time a 
loadout can accommodate one customer train. Coal from different silos may arrive simultaneously at the loadouts where they are mixed to obtain the coal quality within the customer's specifications.

Elements from the material handling operations that impact sustainability of the coalmine within the three economic, social and environmental dimensions are represented using oval shapes and are referred to as impacters. Impacters are the elements that affect one or more among economic, social or environmental dimensions of the sustainability. Section 4 contains detailed discussion on the impacters and the relationships between utility indices and impacters. Suppliers provide Equipment, Fuel, Electricity and Material to support the material handling operations of the coalmine. Topsoil on the surface is removed before coal is excavated whereby solid waste (denoted as " $\mathrm{S}$ " in Figure 2) is produced. Diesel energy driven equipment like trucks and shovels consume fuel and produce emissions (denoted as "A" in Figure 2). Nuisance (denoted as "N" in Figure 2) due to noise produced and liquid effluents (denoted as "L" in Figure 2) are two other impacters during the operations. Ash and chemical elements including sulfur, sodium, phosphorous, chlorides and nitrates are delivered as impurities along with coal to customers. These elements are disposed in the form of air emissions and solid ash after combustion. Other than those that are absorbed in rehabilitation procedure and air emission control equipment, the rest is released into atmosphere.

There are personnel at the mine known as fleet managers who take decisions to route the coal from pits to loadouts in order to load trains with the customer specified quality. Fleet managers use truck fleet management software for setting exact decision variables that control the coal route in the mine. These decision variables are available as options in the fleet management software. Figure 3 illustrates the use cases involved in the use of fleet management software. Fleet managers, truck operators and the following equipments/machinery at the coalmine- trucks, shovels, hoppers, silos and conveyors are represented as "actors". Route Trucks, Assign Truck Operators, Assign Shovels to Pits, Set Hopper-Silo Connections and Set Silo Blend Values are represented as "use cases", each of which involves decision variables available as options in the fleet management software. For example, Assign Truck Operators involves choosing the number of trucks to use from the list of trucks that are active and available, and then assigning specific operators to chosen trucks. Assign Shovels to Pits option involves assigning specific shovels to pits that are active and available. Route Trucks option in the software essentially involves locking trucks to shovels for getting loaded with coal and to hoppers for dumping the coal. Through Set Hopper-Silo Connections option, the fleet managers choose a silo corresponding to each hopper to route the coal via conveyors. To load each train at the loadouts the fleet managers choose the quantity of coal to be extracted from each silo. This quantity is expressed as a percentage out of the total capacity of the train and the corresponding option in the fleet management software is Set Silo Blend Values. The fleet managers may choose to change the values of some or all of the above-mentioned options in the software multiple times during the period trains are at the loadouts. They may utilize the real-time information from the coalmine to set the values of these options and this action is represented as a use case that extends the other use cases in Figure 3.

Figure 4 depicts an overview of the data warehouse infrastructure used to report real-time information from the coalmine to the fleet managers. There are sensors installed on various machineries like trucks, shovels, hoppers, and silos in the coalmine to record their real-time statuses. The information about the expected arrivals of trains is retrieved from an Enterprise Resource Planning system (ERP). The real-time information from these sensors and the ERP system is raw and not in a reportable format. So, it is transformed in two stages using Extract, Transform and Loading (ETL) procedures into a format that is readily usable by reporting software. The raw data from sensors and the ERP system undergoes the first transformation and stored in production server. An ETL transformation is again performed on the data in the production server and stored in the intermediate server. The intermediate server contains data in format that is readily usable by reporting software. This software summarizes the information to present it in form of graphs and plots. It is used by fleet managers for monitoring and planning the material handling operations. 


\section{UTILITY INDICES FOR REAL-TIME INFORMATION}

Real-time Information from different components of the material handling network of the coalmine are generated via sensors and stored in the data warehouse shown in Figure 4. Indices proposed to indicate the utility for some of the real-time information are described in Table 2. Each index contains six attributes: name, impacter, impacter limits, number of information sources for each impacter, update frequencies from each source, and utility. The different impacters are defined in Section 3. These indices are assigned impacters that are relevant to data contained in the corresponding real-time information.

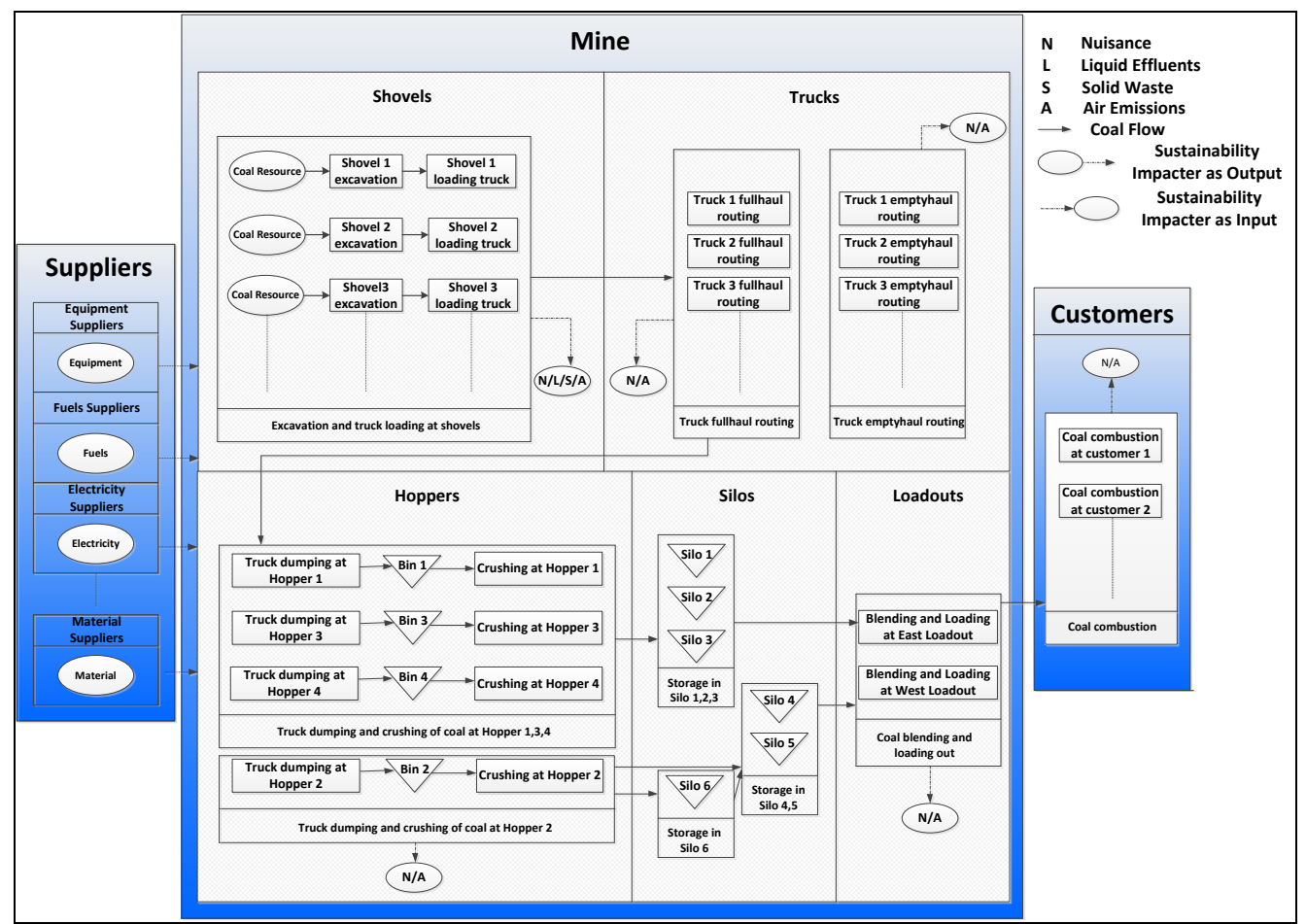

Figure 2: Material handling operations in the coal mine and effects on sustainability of the coalmine

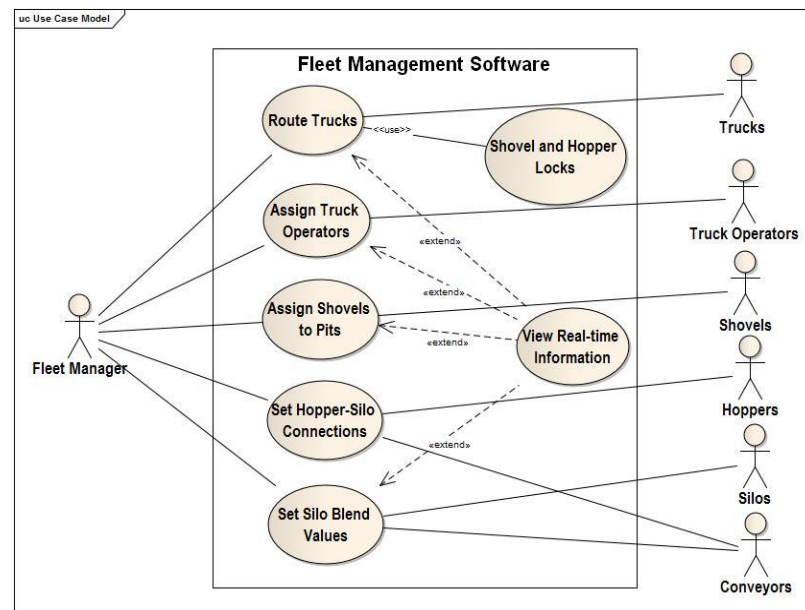

Figure 3: Use case diagram showing the use of fleet management software

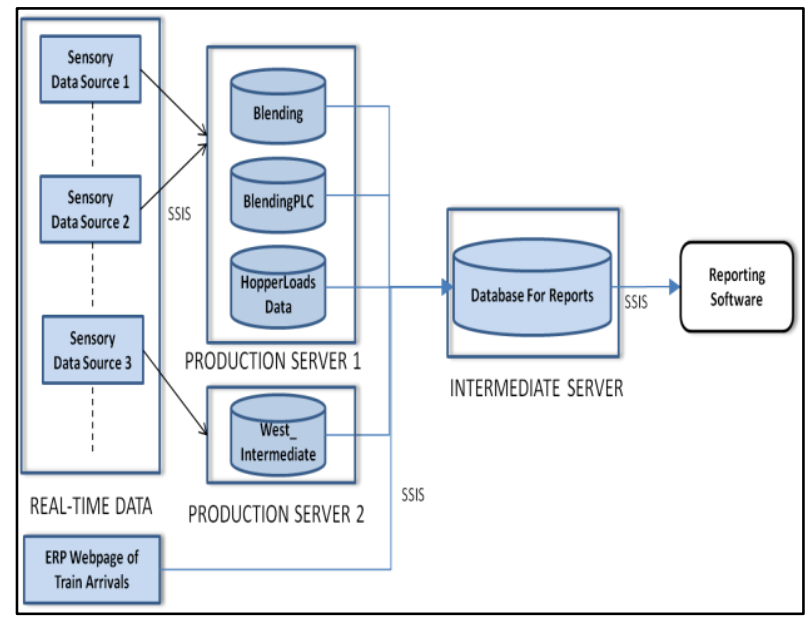

Figure 4: Data warehouse for reporting real-time information at the coalmine 
Number of Information Sources for Each Impacter is the number of different sources of information from which the value of impacter is obtained. Limits are set by each source (coalmine or customer or regulatory agencies; in this paper they are set by authors based on overview of the mine) for the real-time value of impacter to avoid negatively impacting the impacter's dimension(s) of sustainability. Update Frequencies from Each Source is the frequency at which each source mentioned above updates the values of impacters and impacter limits. Figure 5 describes the classification for impacters mentioned in Table 2. Although not illustrated in Figure 5, the indices are also classified into one or more of the categories that their impacter(s) belong to. The different categories proposed are: Economic, Social, Environmental, Operational, Non-Operational. Economic, Social and Environmental categories indicate the corresponding dimension of sustainability that is impacted by the impacter. The other two categories indicate whether the information about the impacters are obtained during the operations including excavation of coal by shovels to loading of coal into customer trains (operational) or otherwise (nonoperational). The purpose of classification of impacters into Economic, Social and Environmental categories is to relate the effect of information through the corresponding impacters on the sustainability of the coalmine. The purpose of classification into operational and non-operational categories is to determine the utility indices that require frequent monitoring (operational).

Table 2: Utility indices for real-time information and attributes

\begin{tabular}{|c|c|c|c|}
\hline Index name & Impacters & $\begin{array}{c}\text { Number of } \\
\text { information } \\
\text { sources for each } \\
\text { impacter }\end{array}$ & Update frequencies from each source \\
\hline Ash Information & Ash & $\begin{array}{l}2 \text { (each from pit and } \\
\text { customer) }\end{array}$ & $1 /$ shift; $1 /$ train \\
\hline Sulfur Information & Sulfur & $\begin{array}{l}2 \text { (each from pit and } \\
\text { customer) }\end{array}$ & $1 /$ shift; $1 /$ train \\
\hline Sodium Information & Sodium & $\begin{array}{l}2 \text { (each from pit and } \\
\text { customer) }\end{array}$ & $1 /$ shift; $1 /$ train \\
\hline Pit Information & $\begin{array}{l}\text { Solid Waste; Land Use; } \\
\text { Health and Safety; Liquid Effluents }\end{array}$ & 1 (from mine) & $1 /$ hour \\
\hline Shovel Information & $\begin{array}{l}\text { Solid Waste; Air Emissions; } \\
\text { Energy Use; Health and Safety }\end{array}$ & 1 (from mine) & $\begin{array}{l}\text { 1/hour for impacters } 1,3 \text { and } 4 ; 1 / 10 \text { minutes for } \\
\text { impacter } 2\end{array}$ \\
\hline Truck Information & $\begin{array}{l}\text { Air Emissions; Nuisance } \\
\text { Energy Use; Health and Safety }\end{array}$ & 1 (from mine) & $\begin{array}{l}1 / 10 \text { minutes for impacters } 1,2 ; 1 / \text { hour for } \\
\text { impacters } 3 \text { and } 4 \text {; }\end{array}$ \\
\hline Conveyors Information & Nuisance; Energy Use & 1 (from mine) & $\begin{array}{l}1 / 10 \text { minutes for impacter } 1 \\
1 / \text { hour for impacter } 2\end{array}$ \\
\hline Silo Information & $\begin{array}{l}\text { Nuisance; Energy Use } \\
\text { Health and Safety }\end{array}$ & 1 (from mine) & $\begin{array}{l}1 / 10 \text { minutes for impacter } 1 \\
1 / \text { hour for impacter } 2 \text { and } 3\end{array}$ \\
\hline Loadout Information & $\begin{array}{l}\text { Nuisance; Energy Use } \\
\text { Health and Safety }\end{array}$ & 1 (from mine) & $\begin{array}{l}1 / 10 \text { minutes for impacter } 1 \\
1 / \text { hour for impacter } 2 \text { and } 3\end{array}$ \\
\hline Train Information & $\begin{array}{l}\text { Nuisance; Energy Use } \\
\text { Health and Safety }\end{array}$ & 1 (from mine) & $\begin{array}{l}1 / 10 \text { minutes for impacter } 1 \\
1 / \text { hour for impacter } 2 \text { and } 3\end{array}$ \\
\hline $\begin{array}{l}\text { Sustainability Knowledge } \\
\text { Information }\end{array}$ & Sustainability Knowledge & 1 (from mine) & $1 /$ shift or $1 /$ (crew change) \\
\hline Revenue Information & Revenue & $\begin{array}{l}2 \text { (from mine; } \\
\text { customer) }\end{array}$ & $1 /$ train \\
\hline $\begin{array}{l}\text { Employment Policy } \\
\text { Information }\end{array}$ & Employment Policy & 1 (from mine) & $1 /$ shift \\
\hline
\end{tabular}

The utility value indicated by the index for individual real-time information is the sum of the utility values over each of the impacters. The expressions for calculation of utility value for each impacter of an index $i$ are given in (1) and (2). Utility value is calculated as a function of attributes of the index and has effectiveness dimension and efficiency dimension. Fleet managers can observe if the information for routing trucks is effective to keep the impacter value within the specified sustainability limit using (1). They can also observe if the current information update frequency is efficient using (2). Completeness of information is denoted by (3) assuming more number of information sources would enable the coalmine to plan to operate within sustainable limits. Denominator term of (3), where $h: R \rightarrow R^{+}, v_{j, t}, l_{j} \in R^{+}$, $y_{j} \in R^{+}$is a constant and $v_{j, t}$ is the value of impacter $j \in Z^{+}$at time $t$, is included to decrease the value of 
utility in case the operating limit $l_{j}$ is breached as known from the current impacter value. In that term, when $l_{j}$ is upper limit and $v_{j, t} \geq l_{j}, h\left(v_{j, t}-l_{j}\right)=v_{j, t}-l_{j}$, else $h\left(v_{j, t}-l_{j}\right)=0$. When $l_{j}$ is lower limit and $v_{j, t} \leq l_{j}, h\left(v_{j, t}-l_{j}\right)=l_{j}-v_{j, t}$, else $h\left(v_{j, t}-l_{j}\right)=0$. Numerator term of (4), where $z_{j} \in R^{+}$is a constant, is an indicator of the magnitude of the change in the value of the impacter at the particular frequency $f_{j} \in R^{+}$. Since some cost is incurred to update the values of impacters at a particular frequency is a function of $f_{j}$ including cost of maintaining servers to store the information, (4) indicates the ratio of magnitude of update in the value of the impacter to the expenditure in updating it.

$$
\begin{gathered}
U_{\text {effectiveness }}^{i}=\sum_{j=1}^{m} U_{\text {effectiveness }}^{i, j} ; m, i \in Z^{+}, m=\text { total number of impacters for index } i \\
U_{\text {efficiency }}^{i}=\sum_{j=1}^{m} U_{\text {efficiency }}^{i, j} \\
U_{\text {effectiveness }}^{i, j}=\frac{1}{\left(1+h\left(v_{j, t}-l_{j}\right) / l_{j}\right)^{y_{j}}} \\
U_{\text {efficiency }}^{i, j}=\frac{\left(1+\left|v_{j, t}-v_{j, t-\left(1 / f_{j}\right)}\right| / v_{j, t-\left(1 / f_{j}\right)}\right)^{z_{j}}}{f_{j}}
\end{gathered}
$$

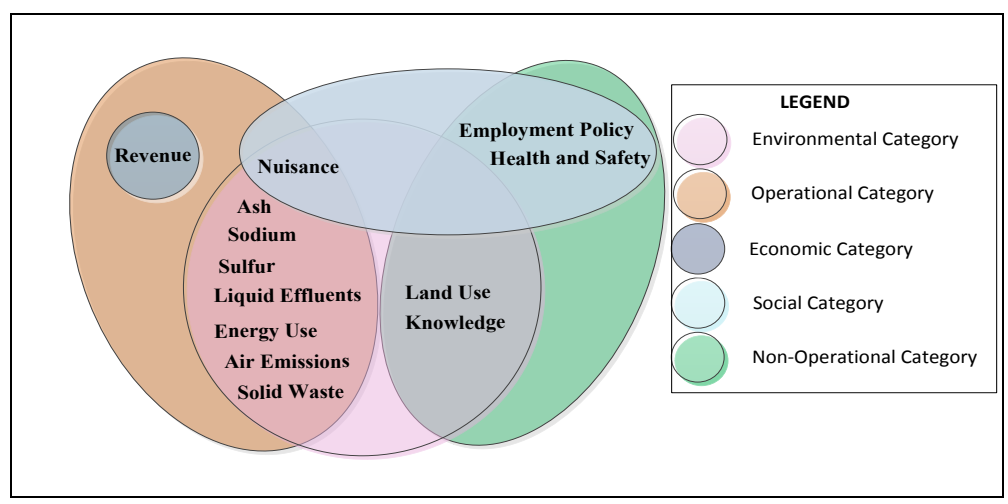

Figure 5: Classification of impacters in different categories

\section{EXPERIMENTS}

As discussed earlier, utility indices are proposed for real-time information from coalmine that can help conduct its operations within sustainable limits. Experiments to obtain the value of air emission impacter from simulations and assess the corresponding utility index-truck information are discussed in this section. The data warehouse shown in Figure 4 contains all the real-time information that records the statuses of machineries in material handling network of the coalmine. The lower half of Figure 6 is a discrete-event simulation model of the material handling network of the mine constructed in Arena. The simulation model can be used to perform what-if analyses using real-time information and obtain the configuration of those decision variables that according to the fleet managers give the best performance. The flow logic of blocks and elements follows the coal flow direction in the material handling network of the coal mine. Significant efforts were spent in formulating the logic to minimize the time to obtain the outputs and at the same time minimize the loss in accuracy of the outputs. The time sequence diagram in Figure 7 shows the procedure that the fleet manager could apply using the simulation model and the utility indices to conduct the mining operations within sustainable limits. The first half of Figure 6 displays a user interface developed in MS Excel used to view the most recent real-time information. The step by step procedure for running the simulator is as follows: 1) the fleet manager activates the user interface to obtain the most recent real-time information; 2) the user interface obtains the data from the data warehouse, stores in the simulator database while also displaying them via pivot tables; 3) the fleet manager views the information, modifies inputs to the user interface and activates the simulator; 4) the simulator reads a combination of modified and original inputs, runs and outputs the results; 5) the fleet manager views these results and decides to run more what-if analyses if deemed required; 6) after a 
number of what-if analyses the fleet manager inputs the configuration of the decision variables that gives the best outputs, into the fleet management software.

The availability of truck information is classified into three levels according to percentage of information available. According to the percentage of trucks whose information are known, three percentage levels are defined, which are Low level for 0\%-30\%, Medium level for 30\%-70\% and High level for $70 \%-100 \%$. For each level low, medium, high, the corresponding value of number of information resources $(n)$ are 1, 2 and 3, respectively. For example, if it is assumed that 30 trucks are active and among them only 3 trucks are monitored and their information is known, the truck information level would be "Low" and the value of " $n$ " in the experiment would be 1 . Values of $y_{j}$ and $z_{j} \forall j$ in (3) and (4) are equal to 2 throughout the experiments. The average route times between pits and dumps are available from the data warehouse. The amount of air emissions produced is calculated using average route times and air emission rates of trucks. Also full trucks (loaded trucks) have higher emission rate, therefore air emissions are evaluated based on truck status (empty, full) in the experiment. In each setting, 27 trucks including 14 new trucks and 13 old trucks are active and 20 trucks are needed for 4 hours of simulation and 10 replications. Combustion engines in old trucks have less efficiency than those in new trucks and thus produce more air emissions. A higher basic emission factor is assigned to old trucks when compared with new trucks. The actual emission rate is the product of particular emission release rate and basic emission factor.

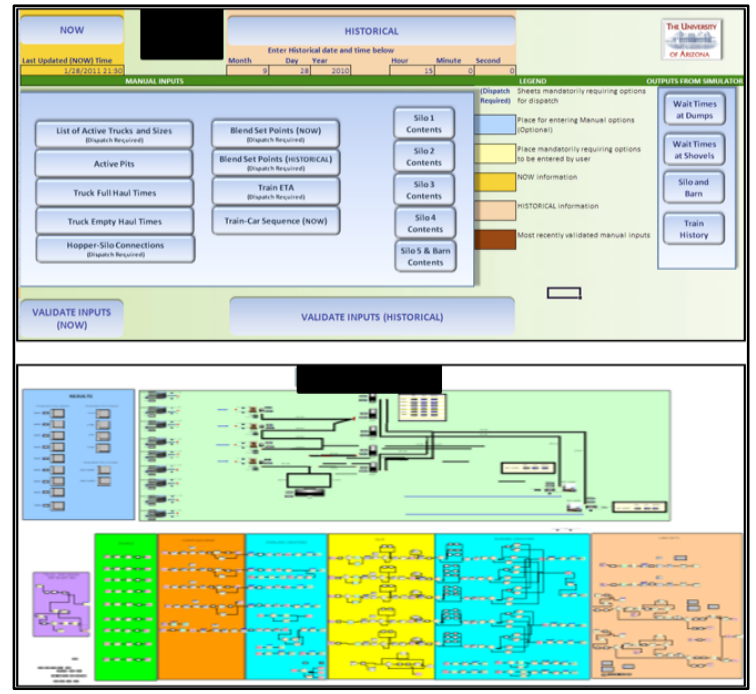

Figure 6: User Interface and Arena Simulator of material handling network

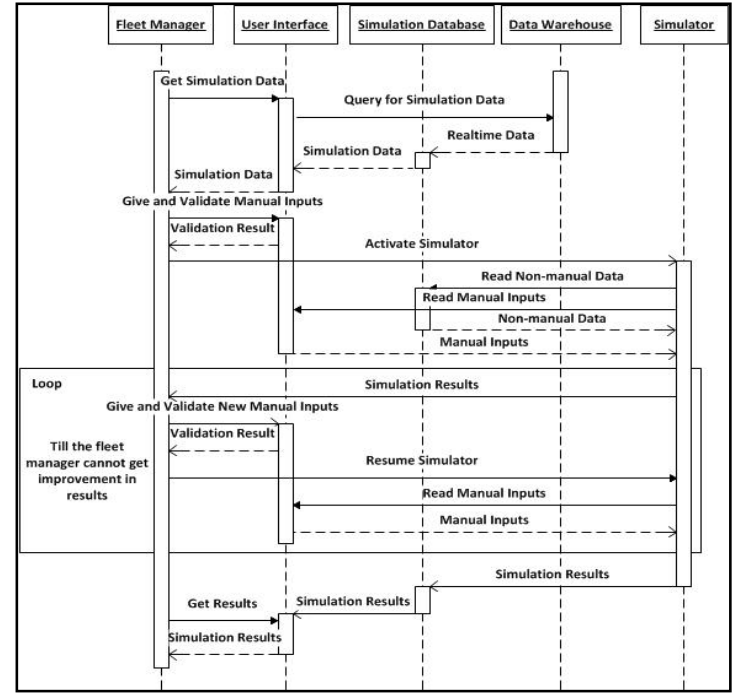

Figure 7: Time-sequence diagram for validation of information utility indices

Different what-if analysis tests are performed to analyze how truck information affects the amount of air emissions released (Table 3). In each setting, truck information level and data update frequency are assumed to be known. Based on available truck information, different truck lock configurations are tested. The purpose of this what-if analysis is to investigate how the level of information, truck selection rules and availability of information affects the sustainability through air emissions impacter. From Figure 8(a), the total PM emission in settings 1-4 and 13-14 where information levels are low are greater than that in other settings with higher information levels. This reveals that with more information, fleet managers will be able to make better selections among trucks based on each truck's actual emission rate. Besides, under same information levels, using old trucks whose conditions are known are likely to produce less air emissions since more chances are that old trucks with unknown conditions produce more emissions because of lack of monitoring their condition and implementing necessary emission control procedures. 
Table 3: What-If analysis data

\begin{tabular}{|c|c|c|c|c|c|c|c|}
\hline $\begin{array}{l}\text { Setting/Case } \\
\text { Number }\end{array}$ & $\begin{array}{l}\text { Truck } \\
\text { Info. } \\
\text { Level }\end{array}$ & $\begin{array}{c}\text { Data update } \\
\text { frequency } \\
\text { (hourly) }\end{array}$ & $\begin{array}{c}\text { No. of trucks } \\
\text { (information } \\
\text { known) }\end{array}$ & $\begin{array}{c}\text { No. of old } \\
\text { trucks } \\
\text { (information } \\
\text { known) routed }\end{array}$ & $\begin{array}{c}\text { No. of new } \\
\text { trucks } \\
\text { (information } \\
\text { known) routed }\end{array}$ & $\begin{array}{l}\text { No. of old trucks } \\
\text { (information } \\
\text { unknown) routed }\end{array}$ & $\begin{array}{l}\text { No. of new trucks } \\
\text { (information } \\
\text { unknown) routed }\end{array}$ \\
\hline 1 & Low & 2 & 5 & 3 & 2 & 3 & 12 \\
\hline 2 & Low & 2 & 5 & 0 & 2 & 6 & 12 \\
\hline 3 & Low & 3 & 5 & 3 & 2 & 3 & 12 \\
\hline 4 & Low & 3 & 5 & 0 & 2 & 6 & 12 \\
\hline 5 & Medium & 2 & 15 & 6 & 7 & 0 & 7 \\
\hline 6 & Medium & 2 & 15 & 3 & 7 & 3 & 7 \\
\hline 7 & Medium & 2 & 15 & 5 & 7 & 3 & 5 \\
\hline 8 & Medium & 3 & 15 & 6 & 7 & 0 & 7 \\
\hline 9 & Medium & 3 & 15 & 3 & 7 & 3 & 7 \\
\hline 10 & Medium & 3 & 15 & 5 & 7 & 3 & 5 \\
\hline 11 & High & 2 & 27 & 6 & 14 & 0 & 0 \\
\hline 12 & High & 3 & 27 & 6 & 14 & 0 & 0 \\
\hline 13 & Low & 2 & 0 & 0 & 0 & 6 & 14 \\
\hline 14 & Low & 3 & 0 & 0 & 0 & 6 & 14 \\
\hline
\end{tabular}

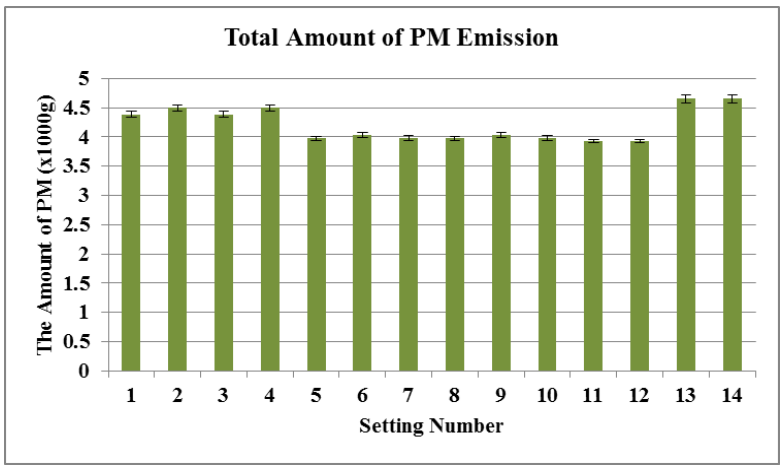

$8(\mathrm{a})$

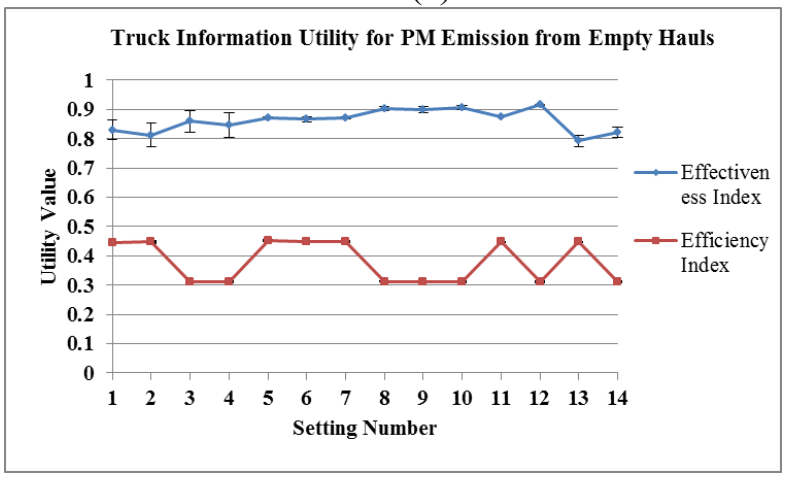

$8(\mathrm{c})$

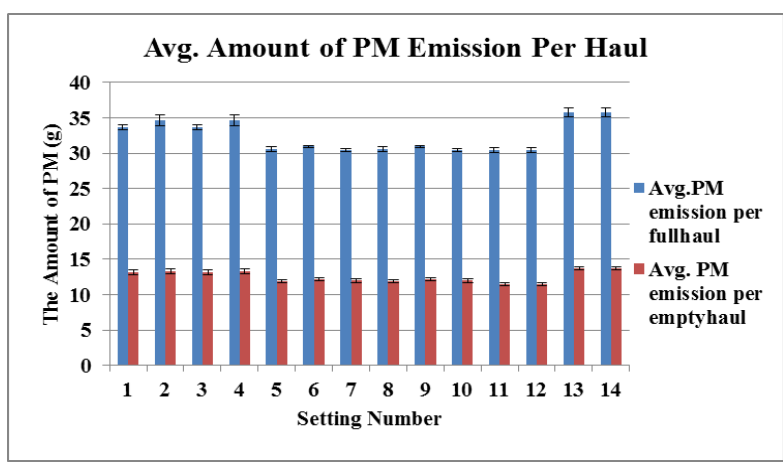

$8(\mathrm{~b})$

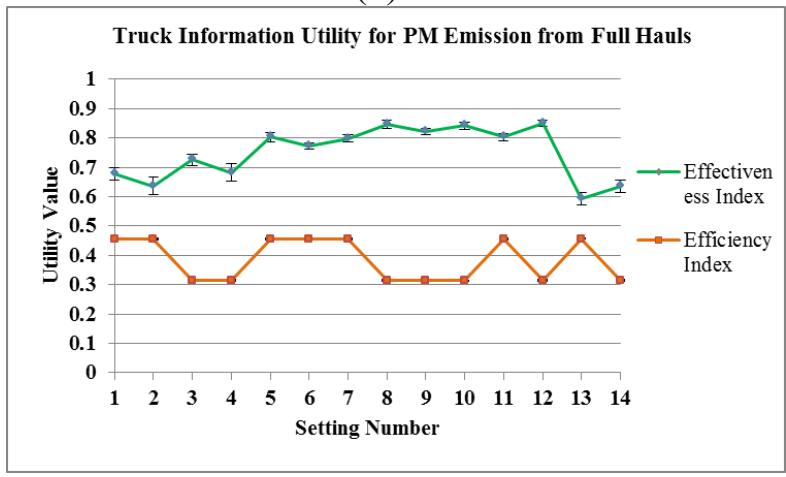

$8(d)$

Figures 8(a) to 8(d): PM emissions and utilities indices for truck information for full haul and empty hauls

The travel of full or loaded trucks from shovels to hoppers is called full haul and travel of empty trucks from hoppers to shovels is called empty haul. For average PM emissions per full/empty haul, the results show the similar trends as indicated in Figure 8(b). Since the average route times for different trucks are assumed to remain the same, choosing different trucks for the same shovel-dump lock don't change the amount of coal mined and dumped. Experiment results for $\mathrm{NO}_{\mathrm{x}}, \mathrm{CO}_{2}, \mathrm{CO}$ and $\mathrm{HC}$ also follow the same trend and therefore the graphs are not included. As shown in Figures 8(c) and Figure 8(d), the values for effectiveness from the first four and last two settings are lower than others, which mean the current truck information is not as effective as those in other settings. In settings with low value for 
effectiveness of information, emission levels are higher than in the settings with higher effectiveness of information as indicated in Figure 8(a) and Figure 8(b). This is because low value for effectiveness dimension of utility of truck information corresponds to the setting where fleet managers are unable to take decisions regarding trucks that decrease negative impact on sustainability of the coalmine. Although higher data update frequency allows fleet managers to minimize delay to make a decision, expending more energy and cost cannot be avoided, which lead to a lower value for efficiency dimension of utility.

\section{CONCLUSION}

In this paper, indices are proposed for evaluating utilities of real-time information from surface coalmines. One of the largest coalmines in North America is considered as case study. Attributes are defined for the indices and then are classified into different categories based on their nature and impact on economic, social or environmental dimension of sustainability. Utility indices are defined for real-time information to help the coalmine conduct its operations within sustainable limits. A discrete-event simulation model of the material handling network of the considered coalmine is constructed in Arena and is used to perform what-if analyses using real-time information for illustrating one of the proposed utility indices. In experiments, different levels of truck information are tested. Based on the impacter values obtained from simulation for each information availability level, a group of truck lock configurations are set attempting to find the one makes the operation within sustainable limits. It is shown through results that the availability of truck information affects sustainability of coal mining operations, and availability of truck information is indicated through effectiveness dimension of utility index for truck information. Fleet managers will be able to set locks such that emissions produced are within the sustainable limit by acting upon the low value of the utility index and then utilizing more information. The following items are planned for future work: updates will be made to expressions of utility functions based on the results from implementing real operational configurations in simulation model and utility indices will be validated based on real performance data such as production data of the mine.

\section{REFERENCES}

Azapagic, A. 2004. "Developing a Framework for Sustainable Development Indicators for the Mining and Minerals Industry," Journal of Cleaner Production, 12:639-662.

Barney, J. 1991. "Firm Resources and Sustained Competitive Advantage". Journal of Management, 17:99-120.

Chadwick, M. J., N. H. Highton, and N. Lindman. 1987. Environmental Impacts of Coal Mining and Utilization. New York: Pergamon Press.

Franks, D., D. Brereton, and C. J. Moran. 2008. "Coal Mining: Managing the Cumulative Impacts of Multiple Mines on Regional Communities and Environments in Australia." Proceedings of the IAIA IAIAAMCEE Special Topic Meeting. Calgary, Canada, 1-24.

Freme, F. 2010. "Coal Review”. Mining Engineering, 62:53-64.

Irving, W., and O. Tailakov. 1999. " $\mathrm{CH}_{4}$ Emissions: Coal Mining and Handling." Good Practice Guidance and Uncertainty Management in National Greenhouse Gas Inventories.

Lucas, J. R., D. R. Maneval, and W. E. Foreman. 1979. "Plant Waste and Environmental Considerations." In Coal Preparation. 4th ed., edited by J. W. Leonard, Chapter 17:1-73. New York: AIME.

Miller, B. G. 2011. Clean Coal Engineering Technology. Burlington, MA: Butterworth-Heinemann.

Mudd, G. M. 2009. "The Sustainability of Mining in Australia: Key Production Trends and Their Environmental Implications for the Future." Research Report No RR5, Department of Civil Engineering, Monash University and Mineral Policy Institute.

Nageshwaraniyer, S. S., Y. J. Son, and S. Dessureault. 2011. "Simulation Based Optimal Planning for Material Handling Network in Mining." In Proceedings of the 2011 IERC. Reno, Nevada, May 21-25.

National Mining Association 2011. Fast Facts. Accessed May 29. http://www.nma.org/statistics/ fast_facts.asp. 
Schmidt, N-H., K. Erek, L. M. Kolbe, and R. Zarnekow 2009. "Towards a Procedural Model for Sustainable Information Systems Management." Proceedings of HICSS '09. 42nd Hawaii International Conference on Systems Science. Hawaii, USA, 1-10.

Schmiermund, R. L., and M. A. Drozd. 1997. "Acid Drainage and Other Mining-Influenced Waters (MIW)." In Mining Environmental Handbook: Effects of Mining on the Environment and American Environmental Controls on Mining. Edited by J. J. Marcus, 599-617. London: Imperial College Press.

Sengupta, M. 1993. Environmental Impacts of Mining: Monitoring, Restoration, and Control. Boca Raton, Florida: Lewis Publishers.

Tomiyama, T. 2001. "Service Engineering to Intensify Service Contents in Product Life Cycles." In Proceedings of EcoDesign 2001: 2nd International Symposium On Environmentally Conscious Design And Inverse Manufacturing. Tokyo, Japan, 613-618.

United Nations General Assembly. 2005. "2005 World Summit Outcome”, Resolution A/60/1.

U.S. Energy Information Administration. 2011. Entire Quarterly Coal Report October-December 2010. Accessed May 2011. http://www.eia.gov/cneaf/coal/quarterly/qcr.pdf.

World Bank Group. 1998. Coal Mining and Production, Pollution Prevention and Abatement Handbook. Accessed July 1998. http://www.natural-resources.org.minerals/CD/docs/twb/PPAH/52.coal.pdf.

World Commission on Environment and Development. 1987. Our Common Future. Oxford, New York: Oxford University Press.

\section{AUTHOR BIOGRAPHIES}

SAI SRINIVAS NAGESHWARANIYER is a Ph.D. student in the Department of Systems and Industrial Engineering at The University of Arizona. His research interests are in the areas of Coal mining and transport logistics, Distributed simulations of complex systems, and Meta-heuristics. He is a member of IIE and INFORMS. He can be reached at nageshwa@email.arizona.edu.

CHAO MENG is a Ph.D. student in the Department of Systems and Industrial Engineering at The University of Arizona. His research interests are in simulation modeling in manufacturing systems, transportation logistics and optimization algorithms. He can be reached at meng@email.arizona.edu

YOUNG-JUN SON is Professor of Systems and Industrial Engineering and Director of Advanced Integration of Manufacturing Systems and Technologies Center at The University of Arizona. His research focuses on the coordination of a multi-scale, networked-federated simulation and decision model needed for design and control in extended manufacturing enterprise, water-environment-energy nexus, homeland security, and social network. He has received several research awards such as the SME 2004 Outstanding Young Manufacturing Engineer Award, the IIE 2005 Outstanding Young Industrial Engineer Award, the IERC Conference Best Paper Awards (2005, 2008, 2009), and Best Paper of the Year Award in 2007 from IJIE. He can be reached at son@sie.arizona.edu

SEAN DESSUREAULT is an Associate Professor at The University of Arizona's Mining and Geological Engineering department where he directs the Mining Information Systems and Operations Management (MISOM) Laboratory, which has a remote operations control room and development facilities where applied research and pre-commercial products are developed. His consulting company MISOM Consulting Services Inc., designs, builds, and services data warehouses and advises corporate leadership on technology strategy. He also pursues sustainable development research and consulting related to political risk, web mining, and sustainable development indicators. He can be reached at sdessure@email.arizona.edu 